\title{
Effects of Tempering Temperature on Wear Resistance and Surface Roughness of a High Speed Steel Roll
}

\author{
Jung Ho LEE, Jun Cheol OH, Joon Wook PARK, ${ }^{1)}$ Hui Choon LEE ${ }^{1)}$ and Sunghak LEE \\ Center for Advanced Aerospace Materials, Pohang University of Science and Technology, Pohang, 790-784 Korea. \\ 1) Roll Manufacturing Division, Inchon Iron and Steel Co., Ltd., Pohang, 790-370 Korea.
}

(Received on March 9, 2000; accepted in final form on April 2, 2001)

\begin{abstract}
The effects of tempering temperature on wear resistance and surface roughness of a high speed steel (HSS) roll manufactured by centrifugal casting method were investigated in this study. Hot-rolling simulation test was carried out using a high-temperature wear tester capable of controlling speed, load, and temperature. The test results revealed that the peak-tempered roll specimen showed the best wear resistance because of its hard matrix. However, its surface roughness deteriorated as the scratching wear proceeded, thereby leading to increase in friction coefficient. In the over-tempered specimens containing numerous fine spherical carbides in the matrix, the abrasive wear occurred predominantly as fine carbides were fallen off from the matrix, and thus the surface roughness was enhanced by the homogeneous wear of both matrix and carbides. These findings suggested that the tempering treatment at temperatures slightly past the peak hardness point would be more desirable in order to improve the wear resistance with consideration of the surface roughness of the HSS roll.
\end{abstract}

KEY WORDS: high speed steel roll; wear resistance; abrasive wear; surface roughness; hot-rolling simulation test; MC carbide.

\section{Introduction}

Major wear mechanism in rolls is abrasive wear, in which micro-cutting, surface plastic deformation, and crack initiation simultaneously occur, depending on the shape and hardness of abrasive particles. ${ }^{1,2)}$ In addition, thermal fatigue due to periodic heating and cooling of a roll surface, oxidation wear, fatigue wear, and sticking of a rolled material into a roll surface also affect the roll wear. ${ }^{3-7)}$ Such a tribology in hot rolling is a microscopic and dynamic phenomenon occurring in the interface between the roll and rolled material, wherein dynamic, thermal, chemical, and metallic factors are working.

During hot rolling, the roll surface in direct contact with the high-temperature rolled material is exposed to damages due to friction with the rolled material, surface fragmentation, and surface roughening, thereby leading to the increase in rolling force and the surface quality deterioration of rolled products. ${ }^{89}$ The increased rolling force is attributed to the increase in the friction coefficient between the roll and rolled material, and poses problems such as size imprecision and defects of rolled products. To improve wear resistance of the roll, thus, surface roughness should also be taken into consideration, and requires a different interpretation from that used in conventional wear mechanisms. Although the wear resistance can be improved by increasing very hard carbides located inside the roll matrix, the resultant hardness difference from the matrix causes serious surface irregularities, thereby deteriorating the surface roughness. The matrix governs the overall roll hardness, and plays a role in fixing carbides. However, studies on the extent of the matrix hardening have yet to be made so that it can work favorably for the simultaneous improvement in both the wear resistance and the surface roughness.

The present study is concerned with the effects of the matrix hardening on wear resistance and surface roughness of a high speed steel (HSS) roll. The HSS roll has excellent resistance to wear and surface roughness, and contains over $10 \mathrm{vol} \%$ of very hard $\mathrm{MC}$ - and $\mathrm{M}_{7} \mathrm{C}_{3}$-type carbides in the tempered martensitic matrix. ${ }^{10,11)}$ High-temperature wear tests which can experimentally simulate the wear and surface roughness occurring during the hot rolling process were conducted. Based on the test results, the mechanisms involved in the wear and surface roughness of the HSS roll were investigated.

\section{Experimental Procedure}

The material used in this study is an HSS roll manufactured by centrifugal casting method, whose chemical composition is $\mathrm{Fe}-2.0 \mathrm{C}-5.0 \mathrm{~V}-3.0 \mathrm{Mo}-1.5 \mathrm{~W}-6.5 \mathrm{Cr}-0.75 \mathrm{Si}-$ $0.35 \mathrm{Mn}-1.0 \mathrm{Ni}-0.003 \mathrm{P}-0.002 \mathrm{~S}$ (wt \%). A small horizontal centrifugal caster was used for producing the experimental roll. Molten metal was poured into a high speed rotating mold to form the shell part. Immediately after solidification, the core part of nodular graphite cast iron was introduced to cast rolls, $400 \mathrm{~mm}$ in diameter (shell thickness; $65 \mathrm{~mm}$ ) and $600 \mathrm{~mm}$ in length. Specimens were obtained from the outer shell part of the roll, and then austenitized at $1050^{\circ} \mathrm{C}$ for three hours, air cooled, and double-tempered at 


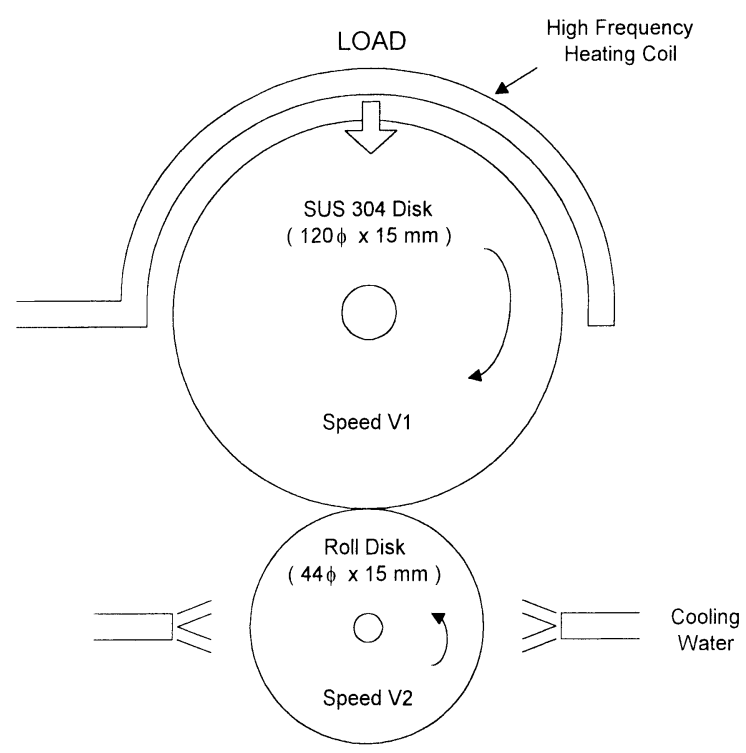

Fig. 1. Schematic diagram of the high-temperature wear tester used for hot-rolling simulation.
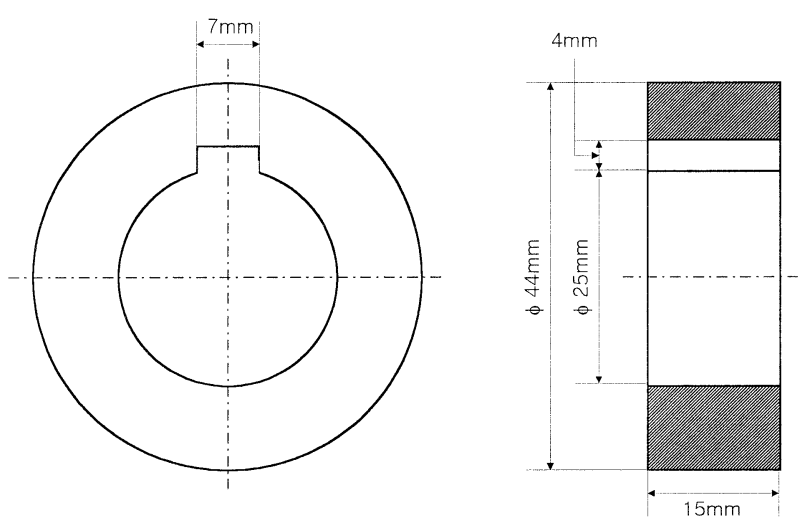

Fig. 2. Shape and dimensions of the wear test specimen. (unit: $\mathrm{mm}$ )

the temperature range from $470^{\circ} \mathrm{C}$ to $600^{\circ} \mathrm{C}$. The doubletempering is a heat-treatment to eliminate retained austenite in the first tempering and then to precipitate fine carbides in the matrix in the second tempering.

The specimens were polished and etched in a $5 \%$ nital solution, and observed by an optical microscope. The carbide volume fractions were quantitatively analyzed by an image analyzer. Overall bulk hardness and matrix hardness were measured by a Vickers hardness tester under $30 \mathrm{~kg}$ and $0.5 \mathrm{~kg}$ load, respectively.

As shown in Fig. 1, both the roll and the rolled material were machined into disks, and then tested by a revolvingdisk-type high-temperature wear tester. Shape and dimensions of the roll specimen are provided in Fig. 2, and an SUS 304 stainless steel was used for the rolled specimen. The rolled specimen was heated by a high-frequency heating coil, and the roll specimen was cooled by water as in actual hot-rolling process. Temperature of the rolled specimen was $850^{\circ} \mathrm{C}$, revolution speed $0.3 \mathrm{~m} / \mathrm{sec}$, rear slip rate $30 \%$, and maximum contact stress was $600 \mathrm{MPa}$ as determined by the Hertz formula. ${ }^{12)}$ Wear amount was evaluated from the weight measurement of the roll specimen in the revolution range from 1000 to 10000 . Friction coefficient $(\mu)$ was calculated from the formula, ${ }^{9}$ )

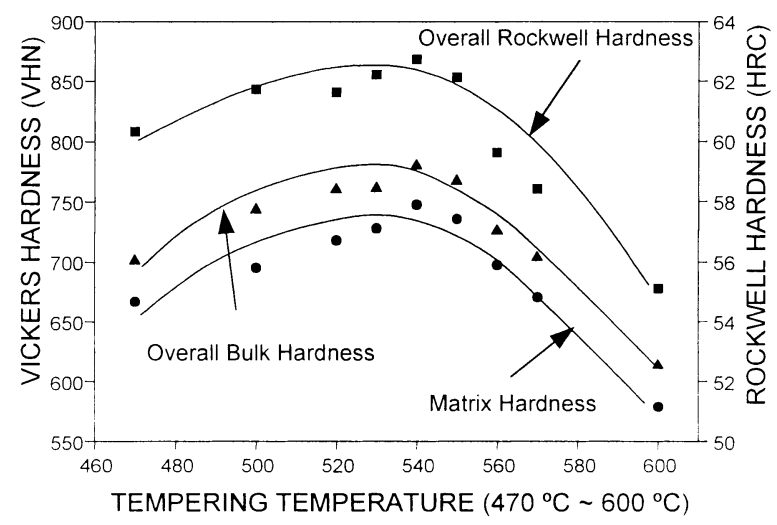

Fig. 3. Overall bulk hardness and matrix hardness as a function of tempering temperature of the HSS roll used.

Table 1. Microvickers hardness and EDS analysis data of MC, $\mathrm{M}_{2} \mathrm{C}$, and $\mathrm{M}_{7} \mathrm{C}_{3}$ carbides.

\begin{tabular}{|c|c|c|c|c|c|c|c|}
\hline \multirow{2}{*}{ Carbide } & \multirow{2}{*}{$\begin{array}{c}\text { Vickers } \\
\text { Hardness* } \\
\text { (VHN) }\end{array}$} & \multirow{2}{*}{$\begin{array}{l}\text { Crystal } \\
\text { Structure }\end{array}$} & \multicolumn{5}{|c|}{ Composition (wt.\%) } \\
\hline & & & W & Mo & $\mathrm{V}$ & $\mathrm{Cr}$ & $\mathrm{Fe}$ \\
\hline MC & 2740 & Cubic & 9.3 & 4.8 & 73.5 & 8.2 & 4.3 \\
\hline $\mathrm{M}_{2} \mathrm{C}$ & 2230 & Hexagonal & 36.6 & 37.1 & 8.6 & 11.1 & 6.5 \\
\hline $\mathrm{M}_{7} \mathrm{C}_{3}$ & 2380 & Hexagonal & 4.4 & 7.7 & 11.1 & 36.9 & 39.8 \\
\hline
\end{tabular}

$$
\mu=T /(P \cdot R)
$$

where $T, P$, and $R$ are torque applied on the revolving axis, vertical load on the roll specimen, and radius of the roll specimen, respectively. After the wear test, surface and cross-section of the roll specimen were observed by a scanning electron microscope (SEM), and average surface roughness was measured by a roughness gage.

\section{Results}

\subsection{Hardness}

Figure 3 is the Vickers hardness test data showing the overall bulk hardness and matrix hardness as a function of tempering temperature. After the hardness reaches a peak at $540^{\circ} \mathrm{C}$, it gradually decreases. Although the overall bulk hardness is higher than the matrix hardness, both show the same tendency. This indicates that the matrix hardness significantly affects the overall bulk hardness when the total carbide fraction is the same. Rockwell hardness values $(\mathrm{C}$ scale) show a similar tendency to those of Vickers hardness.

Table 1 shows the microhardness data of carbides. The hardness of MC carbides formed inside cells is considerably high at $2740 \mathrm{VHN}$, while those of $\mathrm{M}_{2} \mathrm{C}$, and $\mathrm{M}_{7} \mathrm{C}_{3}$ carbides in the intercellular region are 2230 , and $2380 \mathrm{VHN}$, respectively, showing much higher hardness than the martensitic matrix $(650 \mathrm{VHN})$. These microhardness values are close to those reported in previous literatures. ${ }^{13,14)}$

\subsection{Microstructure}

Figures 4(a) and 4(b) are optical micrographs of the roll specimen double-tempered at $540^{\circ} \mathrm{C}$, showing the formation of $\mathrm{M}_{7} \mathrm{C}_{3}$ - and $\mathrm{M}_{2} \mathrm{C}$-type carbides along cell boundaries and strawberry-shaped MC-type carbides inside cells (Fig. 

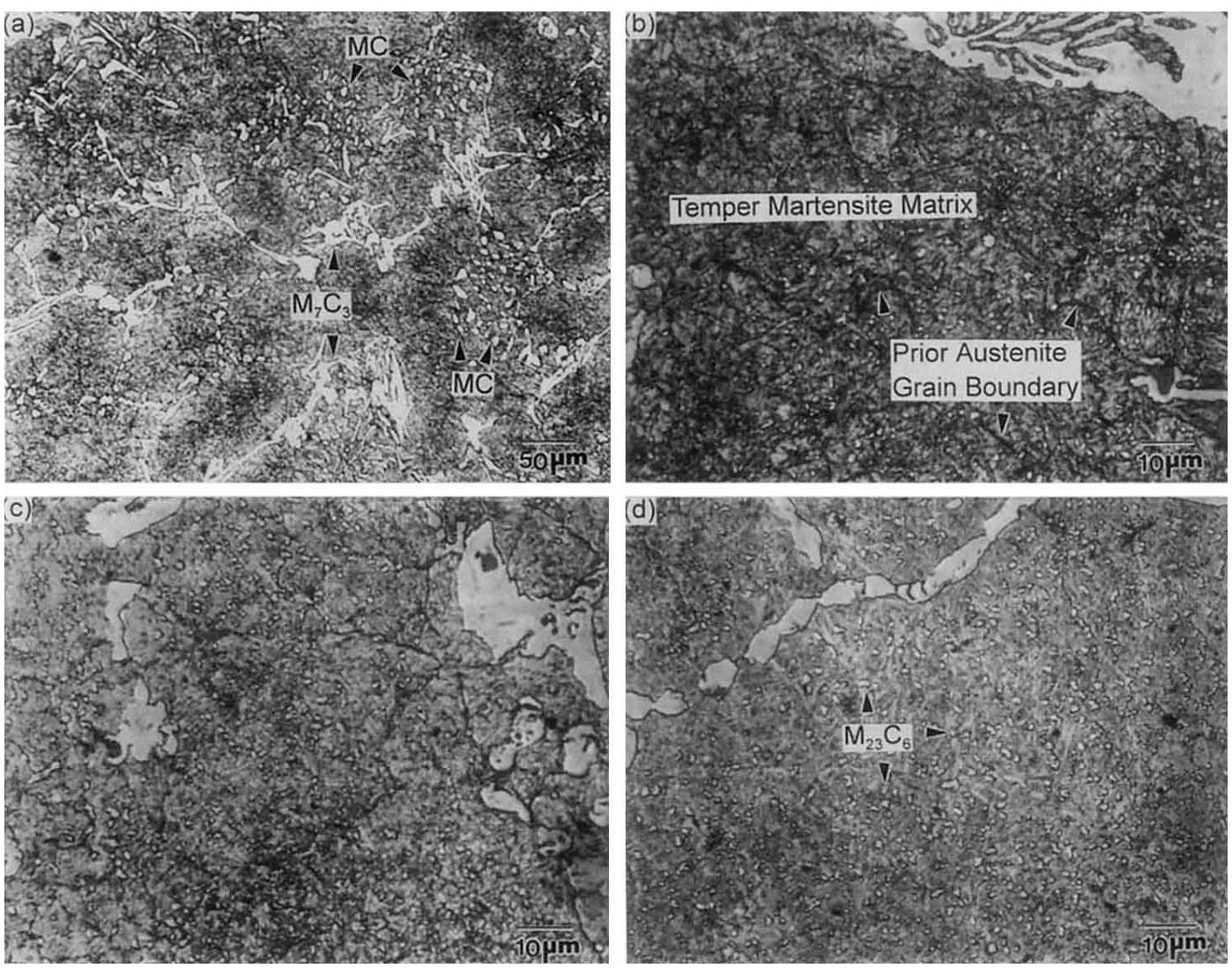

Fig. 4. Optical micrographs of the shell part of the roll specimens tempered at (a) and (b) $540^{\circ} \mathrm{C}$, (c) $570^{\circ} \mathrm{C}$, and (d) $600^{\circ} \mathrm{C} .5 \%$ nital etched.

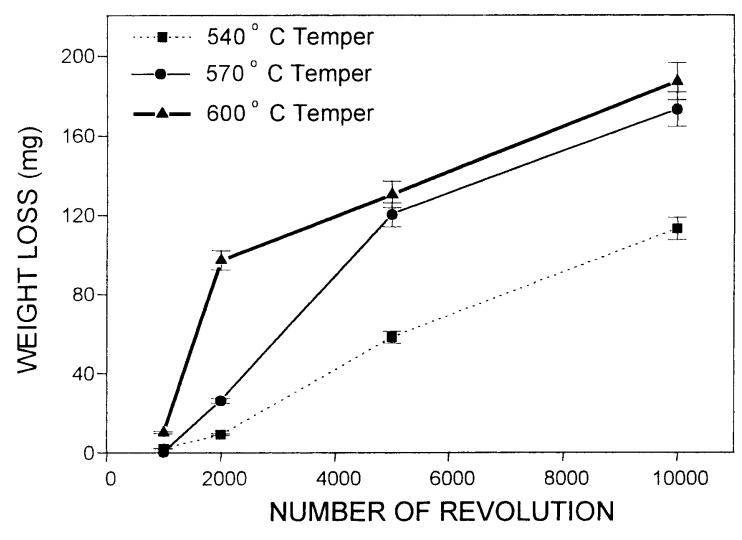

Fig. 5. Weight loss of the disk specimen as a function of number of revolution for the three roll specimens.

4(a)). Although $\mathrm{M}_{2} \mathrm{C}$ carbides are formed due to the addition of $\mathrm{W}$ and $\mathrm{Mo}$, their volume fraction is much less than that of $\mathrm{M}_{7} \mathrm{C}_{3}$ carbides, and they are normally formed with $\mathrm{M}_{7} \mathrm{C}_{3}$ carbides. ${ }^{11)}$ Considering $\mathrm{M}_{2} \mathrm{C}$ carbides as $\mathrm{M}_{7} \mathrm{C}_{3}$ carbides, this roll contains about $7 \mathrm{vol} \%$ of $\mathrm{M}_{7} \mathrm{C}_{3}$ carbides and $5 \mathrm{vol} \%$ of MC carbides. Matrix structure of the roll specimen is mainly composed of lath-type tempered martensite, together with some presence of prior austenite grain boundaries formed inside cells (Fig. 4(b)). In the matrix, fine spherical $\mathrm{M}_{23} \mathrm{C}_{6}$-type carbides precipitated by tempering are also observed. ${ }^{15}$ ) Figures 4(c) and 4(d) are optical micrographs of the roll specimens tempered at $570^{\circ} \mathrm{C}$ and $600^{\circ} \mathrm{C}$. The size and fraction of fine $\mathrm{M}_{23} \mathrm{C}_{6}$ carbides increase with increasing tempering temperature, and the prior austenite grain boundary seems to disappear as martensite is further

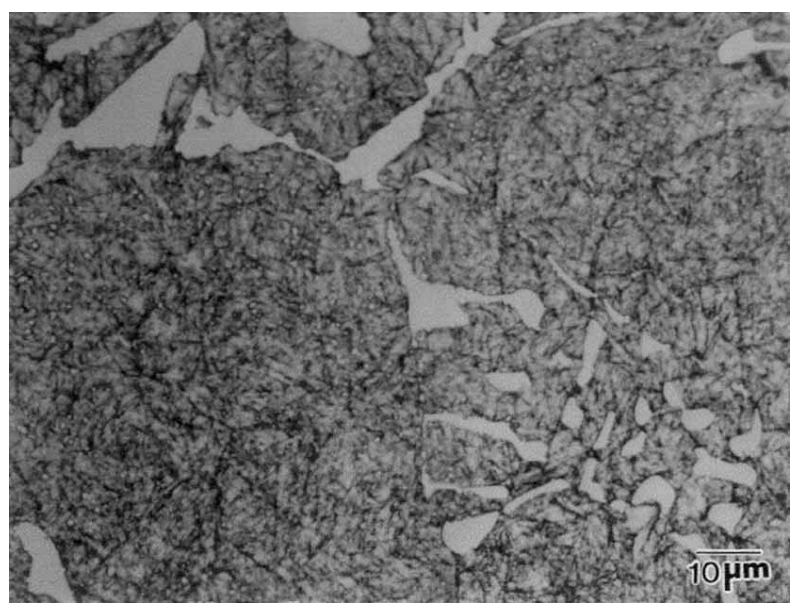

Fig. 6. Optical micrograph of the roll specimen tempered at $540^{\circ} \mathrm{C}$ after 10000 revolutions. $5 \%$ nital etched.

decomposed.

The results of quantitative energy-dispersive spectroscopy (EDS) analyses of $\mathrm{MC}, \mathrm{M}_{2} \mathrm{C}$, and $\mathrm{M}_{7} \mathrm{C}_{3}$ carbides are shown in Table $1 . \mathrm{MC}$ carbides are $\mathrm{V}$-rich carbides $\left(\mathrm{V}_{4} \mathrm{C}_{3}\right.$ in chemical stoichiometry) containing mostly $\mathrm{V}$ with small amounts of $\mathrm{W}, \mathrm{Mo}, \mathrm{Cr}$, and $\mathrm{Fe} . \mathrm{M}_{2} \mathrm{C}$ carbides are carbides containing Mo and $\mathrm{W}$, and $\mathrm{M}_{7} \mathrm{C}_{3}$ carbides are $\mathrm{Cr}$-containing ones.

\subsection{Wear Resistance}

Wear tests were conducted on three specimens, one at $540^{\circ} \mathrm{C}$ showing the peak hardness in Fig. 3 and the other two over-tempered at $570^{\circ} \mathrm{C}$ and $600^{\circ} \mathrm{C}$, and the results are shown in Fig. 5. Figure 6 is an optical micrograph of the 


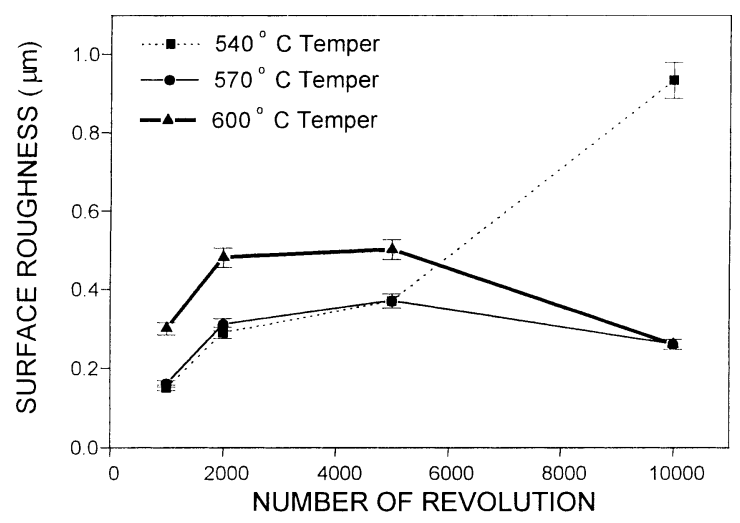

Fig. 7. Surface roughness as a function of number of revolution for the three roll specimens.

specimen tempered at $540^{\circ} \mathrm{C}$ after 10000 revolutions, showing the quite similar microstructure to that before the high-temperature wear test. Its hardness was measured to be $770 \mathrm{VHN}$, which is also comparable to that before the wear test. This confirms that the changes in microstructure and hardness during the high-temperature wear test would be negligible. The wear amount of all the roll specimens increases as the number of revolution and the tempering temperature increase. This is because the wear resistance improves as the matrix hardness increases.

\subsection{Surface Roughness}

Figure 7 provides the surface roughness data of the roll specimens as a function of number of revolution. Since the initial surface roughness of the roll specimens might affect the final surface roughness, the initial surface roughness was measured. All the initial roughness values were very small (about $0.1 \mu \mathrm{m}$ ), and did not vary much for each roll specimen, which confirms that the initial surface roughness would not seriously affect the overall surface roughness. In the roll specimen tempered at $540^{\circ} \mathrm{C}$, the surface roughness steadily increases as the number of revolution rises, whereas those tempered at $570^{\circ} \mathrm{C}$ and $600^{\circ} \mathrm{C}$ show a peculiar trend with the surface roughness increasing in the initial wear stage up to 2000 revolutions, staying unchanged up to 5000 revolutions, and then decreasing. Particularly in the $600^{\circ} \mathrm{C}$-tempered specimen which has the poorest surface roughness in the initial wear stage, the surface roughness is reduced abruptly after 5000 revolutions, showing a better roughness after 10000 revolutions than after 1000 revolutions and eventually showing just the same excellent surface roughness as the $570^{\circ} \mathrm{C}$-tempered specimen.

Changes in the friction coefficient as a function of number of revolution are shown in Fig. 8. Although the friction coefficient is considerably large due to the repeated rolling and sliding friction in the initial wear stage, ${ }^{16,17)}$ it soon reaches the normal state within 100 revolutions. The friction coefficient at the normal state is about the same up to 2000-3000 revolutions, irrespective of the specimens, after which the $540^{\circ} \mathrm{C}$-tempered one shows higher friction coefficient than the $570^{\circ} \mathrm{C}$ - and $600^{\circ} \mathrm{C}$-tempered ones. As the number of revolution increases, the friction coefficient of the $540^{\circ} \mathrm{C}$-tempered specimen increases, whereas those of the $570^{\circ} \mathrm{C}$ - and $600^{\circ} \mathrm{C}$-tempered ones decrease. Comparing this with the surface roughness of Fig. 7 , it is learned that

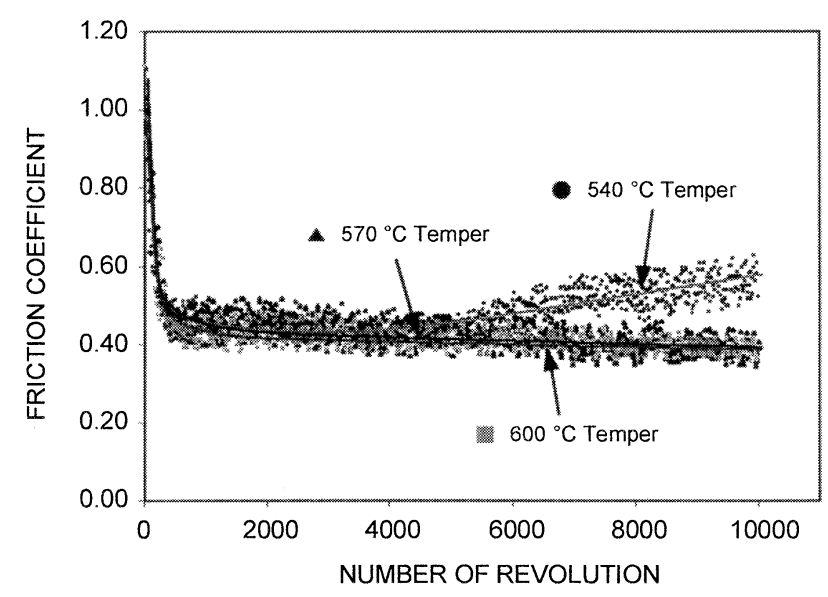

Fig. 8. Friction coefficient as a function of number of revolution for the three roll specimens.

the friction coefficient is related with the surface roughness.

Figures 9(a) through $\mathbf{9 ( d )}$ are SEM micrographs of the worn surface of the roll disk specimens tempered at $540^{\circ} \mathrm{C}$ after $1000,2000,5000$, and 10000 revolutions, respectively. In the initial wear stage, homogeneously worn scratches are observed on the overall surface (Fig. 9(a)). On the slightly worn surface, $\mathrm{M}_{7} \mathrm{C}_{3}, \mathrm{M}_{2} \mathrm{C}$, and $\mathrm{MC}$ carbides are well revealed (arrow-marked), and the extent of wear around $\mathrm{M}_{7} \mathrm{C}_{3}$ and $\mathrm{M}_{2} \mathrm{C}$ carbides is about the same as that of the matrix. Scratches are deeper around MC carbides, particularly deeper in the area densely populated with MC carbides (Figs. 9(b) and 9(c)). Microcracks are also observed between the matrix and MC carbides. The worn surface after 10000 revolutions is heavily damaged, particularly in the area densely populated with MC carbides (Fig. 9(d)).

Figures 10(a) through 10(d) are SEM micrographs of the surface of the $600^{\circ} \mathrm{C}$-tempered specimen. In the initial wear stage, the overall surface is worn homogeneously (Fig. $10(a)$ ), but slightly more worn in comparison with the case of the $540^{\circ} \mathrm{C}$-tempered specimen. In the area densely populated with $\mathrm{MC}$ carbides, microcracks are initiated, and many micropores are observed in the matrix. After 2000 revolutions, micropores formed in the matrix become more numerous, and the wear proceeds centering on them (Fig. 10(b)). After 5000 revolutions, more microcracks are formed, but otherwise not much different from the state after 2000 revolutions (Fig. 10(c)). It shows a grooving phenomenon after 10000 revolutions because many carbides are fallen off, but the worn surface becomes flat since the number of micropores is considerably reduced (Fig. 10(d)).

Figures 11(a) and 11(b) are SEM micrographs of the cross-section of the $540^{\circ} \mathrm{C}$-tempered specimen. After 2000 revolutions, almost flat surface is maintained, with observation of sticking of SUS 304 between some surface prominences (Fig. 11(a)). After 10000 revolutions, more surface prominences are observed in the area densely populated with MC carbides, resulting in the rougher surface than after 2000 revolutions (Fig. 11(b)). In the case of the $600^{\circ} \mathrm{C}$-tempered specimen, severe surface prominences are found even after 2000 revolutions (Fig. 12(a)). This is associated with the falling-off of fine carbides precipitated in the matrix. However, after 10000 revolutions, the surface 
ISIJ International, Vol. 41 (2001), No. 8
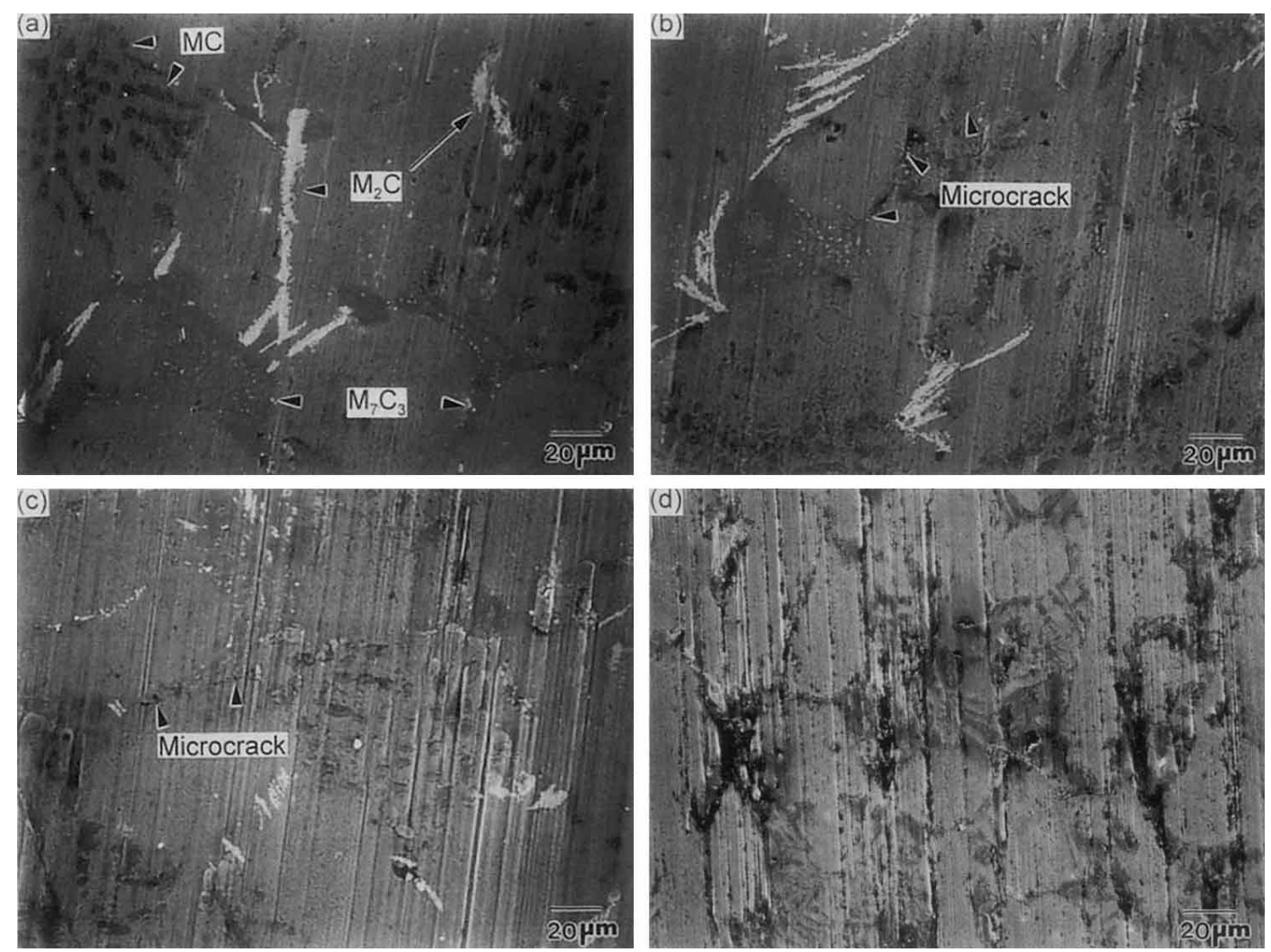

Fig. 9. SEM micrographs of the surface of the roll disk specimens tempered at $540^{\circ} \mathrm{C}$ after (a) 1000 , (b) 2000 , (c) 5000 , and (d) 10000 revolutions.
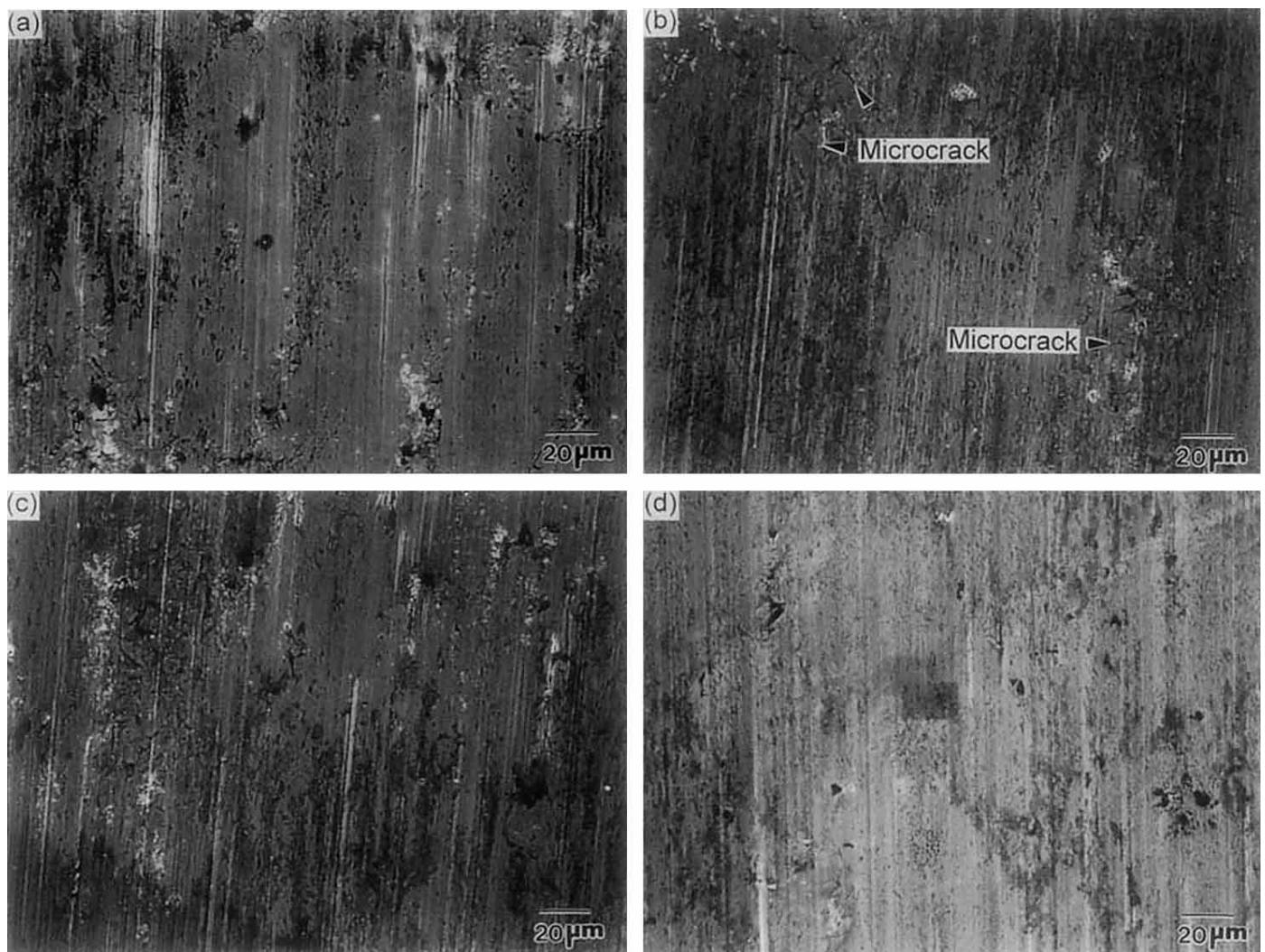

Fig. 10. SEM micrographs of the surface of the roll disk specimens tempered at $600^{\circ} \mathrm{C}$ after (a) 1000 , (b) 2000 , (c) 5000 , and (d) 10000 revolutions. 

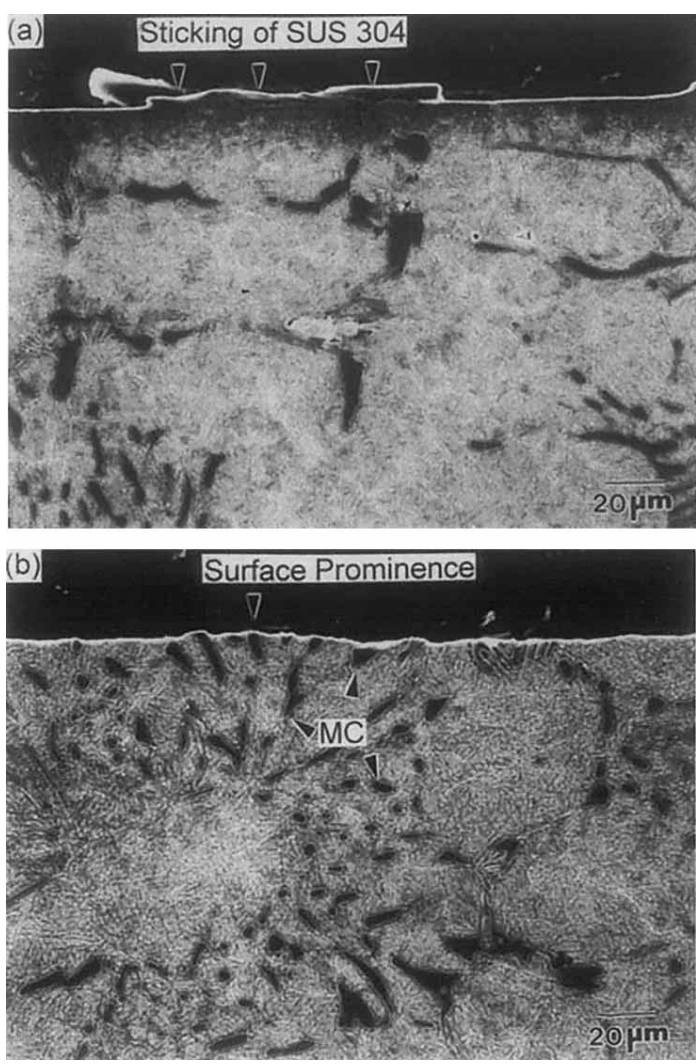

Fig. 11. SEM micrographs of the cross-section of the roll disk specimens tempered at $540^{\circ} \mathrm{C}$ after (a) 2000 and (b) 10000 revolutions.
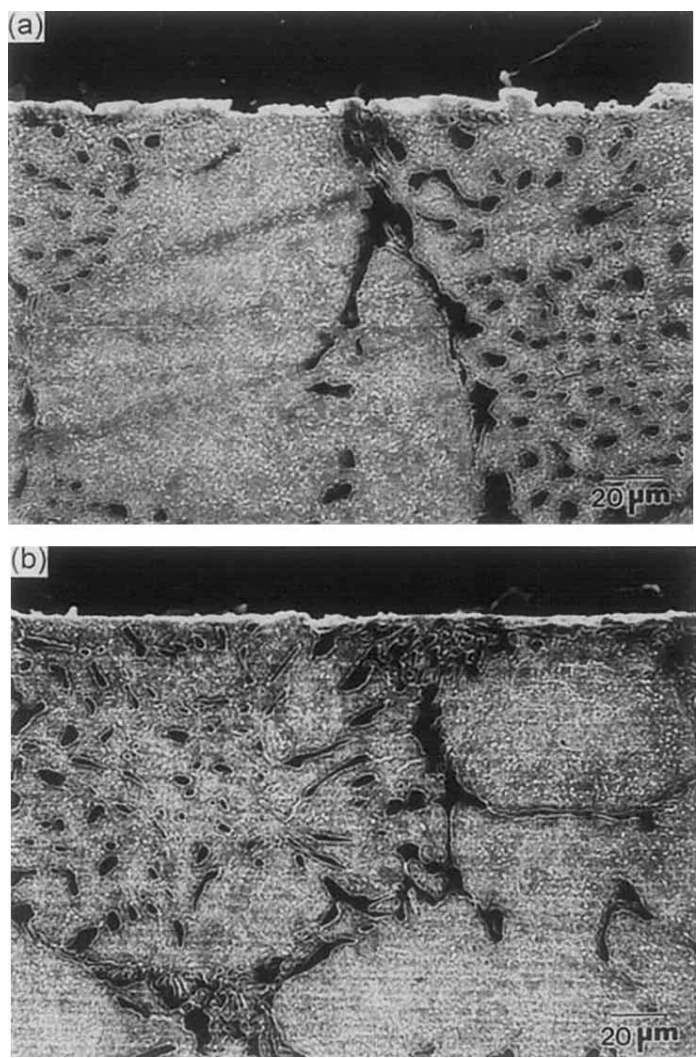

Fig. 12. SEM micrographs of the cross-section of the roll disk specimens tempered at $600^{\circ} \mathrm{C}$ after (a) 2000 and (b) 10000 revolutions. becomes flatter than after 2000 revolutions (Fig. 12(b)).

\section{Discussion}

As observed in Figs. 4(a) through 4(d), microstructural factors affecting the properties of the HSS roll are hard MC and $\mathrm{M}_{7} \mathrm{C}_{3}$ carbides coarsely formed along cell boundaries or inside cells, tempered martensitic matrix, and fine spherical carbides precipitated in the matrix. Since the coarse carbides have very high hardness, they have a direct affect on hardness, wear resistance, and surface roughness, and also significantly influence thermal fatigue and fracture property depending on their shape, volume fraction, and distribution. ${ }^{18-20)}$ The matrix governs the overall bulk hardness, holds up carbides, and is related with fracture toughness. ${ }^{13)}$ Thus, in order to manufacture rolls having excellent properties, these microstructural factors should be optimized in combination. Especially to improve the wear resistance which is the most critical property, it is desirable to form carbides of high hardness inside cells or along cell boundaries discontinuously and homogeneously, and to raise the overall bulk hardness by increasing the matrix hardness. ${ }^{16)}$ In this respect, it is quite obvious that the $540^{\circ} \mathrm{C}$-tempered specimen having the peak hardness would have the better wear resistance than the over-tempered ones (Fig. 5).

However, when the surface roughness is taken into consideration together with the wear resistance, tempering at the peak-hardness point could rather be detrimental. This requires comparative analyses on the wear mechanisms of the peak-tempered specimen and the over-tempered ones. First of all, in the $540^{\circ} \mathrm{C}$-tempered specimen, the tempered martensitic matrix is hard, and the fine carbides precipitated in the matrix are well fixed in the matrix. In the wear process against the rolled material, a number of scratches appear as shown in Fig. 9(a) through 9(d), and its surface becomes rougher as the wear proceeds. Since the coarse hard carbides, particularly MC carbides, are hardly worn, the comparatively ductile matrix is first worn instead, and creates surface prominences around hard carbides due to the less wear here (Fig. 11(b)), thereby resulting in poor surface roughness. The surface roughness variation as a function of number of revolution of Fig. 7 indicates that the abrasive wear becomes increasingly severe with increasing the number of revolution. Owing to this surface roughness, the friction coefficient increases (Fig. 8), which considerably raises the rolling force, and interrupts the hot rolling operation.

On the contrary, since the tempered martensite matrix is considerably softened in the over-tempered specimens and a number of fine spherical carbides are precipitated in the matrix (Figs. 4(c) and 4(d)), the fixing of fine carbides into the matrix is not as good as that in the $540^{\circ} \mathrm{C}$-tempered specimen. These fine carbides can be easily fallen off from the matrix in the initial wear stage. The micropores observed in the worn surface of Fig. 10(a) seem to be the traces of fallen carbides. These fallen fine carbides work as wear debris in the interface between the roll specimen and the rolled material, and cause the abrasive wear to occur. Since this abrasive wear wears coarse hard $\mathrm{MC}$ and $\mathrm{M}_{7} \mathrm{C}_{3}$ carbides as well as the matrix, the surface prominence 
around coarse carbides is reduced as the wear continues, thereby making the surface flat and reducing the friction coefficient.

The high-temperature wear test results indicate that the surface roughness should be simultaneously taken into consideration in order to improve the wear resistance of HSS rolls; thus, requiring different interpretation of wear mechanisms from the conventional wear concept. As the overall bulk hardness and matrix hardness and the volume fraction of fine carbides vary with the tempering temperature, the wear process is accordingly different. In the peak-tempered specimen, the matrix is selectively worn to produce surface prominences around coarse hard carbides, thereby leading to poor surface roughness. On the other hand, in the overtempered specimens, fine carbides fallen off from the matrix work as wear debris, promote the abrasive wear, and then enhance the surface roughness. In order to improve the overall wear property in consideration of the surface roughness, the over-tempered ductile matrix could be evaluated better, in which the abrasive wear by fine carbides can be better promoted despite the lower matrix hardness. Although over-tempering reduces the overall bulk hardness and matrix hardness and deteriorates the wear resistance, optimization of the wear resistance and surface roughness can be achieved when tempered at temperatures sightly past the peak hardness point since the abrasive wear enhances the surface roughness. Because the required hardness of HSS rolls applied to actual rolling stands is about $60 \mathrm{HRC}$ at room temperature, slight over-tempering within the range satisfying the required hardness, say at $560^{\circ} \mathrm{C}-570^{\circ} \mathrm{C}$, seems appropriate to improve the roll performance.

\section{Conclusions}

(1) The high-temperature wear test results indicate that the $540^{\circ} \mathrm{C}$-tempered specimen with the peak hardness has poorer surface roughness than the over-tempered specimens as the wear continues, although its overall wear resistance is better than that of the latter.

(2) The $540^{\circ} \mathrm{C}$-tempered specimen is predominated with a number of scratches since it has hard tempered martensite matrix and fine carbides are well fixed in the matrix. Here, the matrix is selectively worn, and surface prominences are formed around coarse hard carbides, deteriorating the surface roughness.

(3) In the over-tempered specimens in which the tempered martensitic matrix is considerably softened and numerous fine carbides are precipitated in the matrix, fine carbides are readily fallen off from the matrix as the wear starts. They work as wear debris, causing the abrasive wear to occur and accelerating the wear speed. Since this abrasive wear homogeneously wears both the matrix and coarse carbides, the surface roughness improves as the wear proceeds.

(4) Although over-tempering lowers the matrix hardness and deteriorates the wear resistance, it enhances the surface roughness with the abrasive wear. Therefore, when tempered at $560^{\circ} \mathrm{C}-570^{\circ} \mathrm{C}$, slightly past the peak hardness point, the wear resistance and surface roughness can be optimized.

\section{Acknowledgments}

This work has been supported by Inchon Iron and Steel Co, Ltd. The authors thank Professor Nack J. Kim of POSTECH, Dr. Dongwoo Suh of Electronic Telecommunication Research Institute, and Mr. Byung Il Jung, and Dr. Keun Chul Hwang of Inchon Iron and Steel Co, Ltd., for their helpful discussion on the high-temperature wear testing.

\section{REFERENCES}

1) S. Spuzic, K. N. Strafford, C. Subramanian and G. Savage: Wear, 174 (1994), 261.

2) R. Colas, J. Ramirez, I. Sandoval, J. C. Morales and L. A. Ledue: Wear, 230 (1999), 56.

3) K. Mizutani: Tribology in Rolling Process, ISIJ, Tokyo, (1993), 109

4) S. R. Hara: Tribology in Rolling Process, ISIJ, Tokyo, (1993), 131.

5) S. E. Lundberg: J. Mater. Process. Technol., 36 (1993), 273.

6) S. Lee, K.-S. Sohn, C.G. Lee and B. I. Jung: Metall. Mater. Trans. A, 28A (1997), 123.

7) S. Lee, D. H. Kim, J. H. Ryu and K. Shin: Metall. Mater. Trans. A, 28A (1997), 2595.

8) O. Kato, H. Yamamoto and M. Ataka: CAMP-ISIJ, 4 (1991), 462.

9) M. Hashimoto, H. Takigawa and T. Kawakami: 37th MWSP Conf. Proc., ISS, Warrendale, PA, 33 (1996), 275.

10) J. W. Park, H. C. Lee and S. Lee: Metall. Mater. Trans. A, 30A (1998), 399.

11) K. C. Hwang, S. Lee and H. C. Lee: Mater. Sci. Eng. A, $\mathbf{A 2 5 4}$ (1998), 282.

12) J. W. Shingly and C. R. Mischke: Mechanical Engineering Design, McGraw-Hill, New York, NY, (1989), 71.

13) W. F. Smith: Structure and Properties of Engineering Alloys, McGraw-Hill, New York, NY, (1981), Ch. 1, Ch. 9.

14) W. C. Leslie: The Physical Metallurgy of Steels, McGraw-Hill, New York, NY (1981), Ch. 8.

15) S. Karagoz and H. Fischmeister: Steel Res., 58 (1987), 46.

16) P. Thonus, J. C. Herman, J. P. Breyer, M. Sinnaeve, A. Charlier, D. Liquet and R. Marquet: 38th MWSP Conf. Proc., Vol. 34, ISS, Warrendale, PA, (1997), 43.

17) D. Suh, S. Oh, W. Jin and S. Lee: J. Korean Inst. Met. \& Mater, 35 (1997), 673.

18) Y. Sano, T. Hattori and M. Haga: ISIJ Int., 32 (1992), 1194.

19) T. Kudo, S. Kawashima and R. Kurahashi: ISIJ Int., 32 (1992), 1190.

20) K. Goto, Y. Matsuda, K. Sakamoto and Y. Sugimoto: ISIJ Int., 32 (1992), 1184. 